\title{
PHỔI BIỆT LẬP: KINH NGHIỆM CHẨN ĐOÁN VÀ ĐIỀU TR! TẠI BỆHH VIỆN PHỔI TRUNG ƯƠNG
}

\author{
Khiếu Mạnh Cường*, Nguyễn Lê Vinh*, Nguyễn Sỹ Khánh*, Đinh Văn Lương*, \\ Đinh Văn Tuấn*, Đoàn Quốc Hung**,
}

TÓM TẮT: 46 trường hợp (18 nam, 28 nữ) chẩn đoán phổi biệt lập sau phẫu thuật giai đoạn 10/2009 - 07/2016 tại bệnh viện Phổi trung ương. Tuổi trung bình 33,3 $\pm 12,6$ tuổi, 28 trường hợp có tiền sử điều trị các bệnh hô hấp khác nhau. Triệu chứng lâm sàng chủ yếu đau ngực và ho, sốt, khó thở, XQuang ngực thường quy chủ yếu với dạng tổn thương: Mờ không đồng nhất 31,82 $\%$, mờ đồng nhất $27,27 \%$, kén dịch khí $20,45 \%$, kén khí/ hang 18,18\%, đa kén khí 2,27\%. Chẩn đoán xác định dựa trên CT-Scanner ngực có dựng hình mạch máu phát hiện mạch bất thường $84,78 \%$. Hình ảnh tổn thương: khối đặc: 13,04\%, nang dịch $28,26 \%$, mờ không đồng nhất $21,74 \%$, kén dịch khí 15,21\%, kén khí 17,39\%, đa kén khí 4,35\%. Tổn thương bên phải: 18 trường hợp, trái: 28 trường hợp nằm phân thùy sau dưới. Chẩn đoán đúng trước mổ 39/46 (84,78\%) trường hợp. Điều trị với phổi biệt lập trong thùy (40 trường hợp) cắt thùy phổi $95 \%$, cắt phần phổi chứa phổi biệt lập $5 \%$. Phổi biệt lập ngoài thùy $2 / 6$ trường hợp cắt nguyên phổi biệt lập, 3/6 trường hợp cắt phổi biệt lập và 1 phần thùy phổi lân cận, $1 / 6$ trường hợp phải cắt cả thùy phổi. Thời gian nằm viện sau mổ khi không có biến chứng rò thực quản sau mổ trung bình 16,2 $\pm 12,84$ ngày.

Tù khóa: Phổi biệt lập

\section{SUMMARY \\ PULMONARY SEQUESTRATION EXPERIENCES IN DIAGNOSIS AND TREATMENT}

46 cases with pulmonary sequestration were performed from 10/2009 to 07/2016 at National Lung Hospital : Sex ratio: male/female 18/28.
Mean age: $33,3 \pm 12,6.28$ cases with history of lung disease treatment. Image in Xray location of pulmonary sequestration: right /lef $18 / 28$ and all of them were in low lobe at both side with image as Homogeneous shadow $(27,27 \%)$, inhomogeneous shadow $(31,82 \%)$, Fluid level $20,45 \%$, bulae $18,18 \%$, multibulae $2,27 \%$. Image in CT- Scanner: tumer 13,04\%, Fluid cyst $28,26 \%$, inhomogeneous shadow $21,74 \%$, Fluid level $15,21 \%$, bulae $17,39 \%$, multibulae $4,35 \%$. Blood supply were aorta thoracic descendens (27/46 cases) and aorta abdominalis (19/46 case). Correct preoperative diagnosis was in 39/46 cases. Intrapulmonary sequestration's treatment (40 cases) composed: lobectomy 95\% cases, atypic lobectomy 5\%. Extrapulmonary sequestration's treatment 6 cases composed: sequestration's resection: $2 / 6$ cases, sequestration's resection and atypic lobectomy: 3/6 cases sequestration's resection and lobectomy: 1/6 cases. Mean postoperative hospital stay was 16,2 $\pm 12,84$ days (Whithout a case oesophageal fistula).

Keyword: Pulmonary sequestration, intrapulmonary sequestration, extrapulmonary sequestration.

\section{Connect author:}

Khiếu Mạnh Cuòng: xuanmaikmc@gmail.com

Đoàn Quốc Hurng: hung.doanquoc@gmail.com

\footnotetext{
*Bệnh viện Phổi Trung uoong,

** Bệnh viện Việt Đức - Đại học Y Hà Nội Ngưòi chịu trách nhiệm khoa học: PGS.TS. Đoàn Quốc Hung Ngày nhận bài: 01/05/2018 - Ngày Cho Phép Đăng: 20/05/2018

Phản Biện Khoa học: GS.TS. Bùi Đức Phú PGS.TS. Đặng Ngọc Hùng
} 


\section{I. ĐẶT VẤN ĐỀ}

Phổi biệt lập là dị tật bẩm sinh hiếm gặp của phổi, tỷ lệ thấp $1,5 \%$ - 6,4\% trong các dị tật của phổi, không thông với cây phế quản và được cấp máu từ nhánh động mạch chủ. Phổi biệt lập có 2 loại: Phổi biệt lập trong thùy (chiếm > 75\%), Phổi biệt lập ngoài thùy (chiếm $<25 \%$ ). Một số trường hợp có sự liên quan tới các dị tật bẩm sinh khác: rò tiêu hóa, thoát vị hoành,... Năm 1777 , Huber mô tả động mạch bất thường từ động mạch chủ cấp máu cho phần phổi tổn thương. Năm 1861, Rokitansky và Rektorzick mô tả trường hợp phổi biệt lập ngoài thùy. Năm 1946, Pryce mô tả đầy đủ và phân loại hình thái học phổi biệt lập trong thùy và ngoài thùy, ông dùng thuật ngữ "sequestration: biệt lập" có nguồn gốc từ tiếng Latin: sequestrare có nghĩa là riêng biệt [1]. Chẩn đoán xác định nhờ cắt lớp vi tính ngực độ phân giải cao có dựng hình mạch máu. Điều trị phổi biệt lập chủ yếu bằng phẫu thuật. Ở Việt Nam phổi biệt lập hiếm khi được chẩn đoán và can thiệp sớm mà hầu hết được chẩn đoán và điều trị nhầm sang các bệnh lý khác: viêm phổi tái diễn, u phổi, kén phế quản, một số ít được phát hiện tình cờ. Mục tiêu nghiên cứu: "1. Mô tả một số đặc điểm chẩn đoán lâm sàng và chẩn đoán hình ảnh. 2. Mô tả một số đặc điểm điều trị phẫu thuật phổi biệt lập" nhằm giúp chẩn đoán và điều trị sớm dị tật này.

\section{II. ĐỐI TƯợNG VÀ PHƯƠNG PHÁP NGHIÊN CÚU}

\section{1. Đối tượng nghiên cúu}

Nghiên cứu hồi cứu 46 trường hợp được chẩn đoán là phổi biệt lập, điều trị phẫu thuật tại Bệnh viện Phổi Trung ương từ tháng 10 năm 2009 đến tháng 7 năm 2016.

\subsubsection{Tiêu chuẩn lựa chọn}

Tất cả bệnh nhân có hồ sơ bệnh án đủ thông tin nghiên cứu với chẩn đoán sau mổ là phổi biệt lập và giải phẫu bệnh là tổ chức phổi.

\subsubsection{Tiêu chuẩn loại trù̀}

Hồ sơ bệnh án không đủ thông tin, chẩn đoán phổi biệt lập không mổ.

\subsection{Nội dung nghiên cứu:}

- Mô tả một số đặc điểm: Tuổi, giới, tiền sủ bệnh hô hấp, triệu chứng lâm sàng, đặc điểm XQuang, CT-scanner ngục, chẩn đoán, kết quả sóm phẫu thuật.

\subsection{Phuơng pháp thu thập số liệu}

Sử dụng hồ sơ bệnh án có sẵn, khai thác thông tin hồ sơ bệnh án điền vào mẫu bệnh án thống nhất.

\subsection{Phưong pháp xủ lý số liệu}

Xử lý phân tích số liệu bằng phần mềm Stata 10.0 Các thuật toán được sử dụng: tính tỷ lệ \%, tính trung bình, độ lệch, $\mathrm{X} \pm \mathrm{SD}$, các thuật toán kiểm định.

\section{KẾT QUẢ NGHIÊN CỨU}

\section{1. Đặc điểm chung của bệnh nhân}

\subsubsection{Theo tuổi và giới}

Bệnh phát hiện và điều trị phẫu thuật ở trẻ em dưới 16 tuổi (2/46) 4,35\% trường hợp, chủ yếu ở người trưởng thành (44/ 46) 95,65\% trường hợp. Trung bình: $33,3 \pm 12,6$ tuổi, thấp nhất: 11 tuổi, cao nhất: 62 tuổi. Theo giới: 18 nam, 28 nữ.

\subsubsection{Tiền sủ̉ bệnh}

Có 28 trường hợp có tiền sử chẩn đoán và điều trị các bệnh hô hấp: Viêm phổi 21,43\%, Áp xe phổi $19,08 \%$, Viêm hô hấp tái diễn 16,67\%, Lao phổi $14,29 \%$, Giãn phế quản 9,52\%, Ho máu $7,14 \%$, kén phổi 2,38\%, Chấn thương ngực 2,38\%, Viêm mũi dị ứng 2,38\%.

\subsubsection{Triệu chứng chủ yếu}

Có 2 trường hợp phát hiện tình cờ, 44 trường hợp có triệu chứng: Đau ngực 77,27\%, Sốt 51,11\%, Ho đờm 51,11\%, Ho máu 27,27\%, Khó thở $29,55 \%$. 


\subsection{4. Đặc điểm chẩn đoán hình ảnh của phổi biệt lập}

Bảng 3.1: Hình ảnh thương tổn XQuang thường quy và chẩn đoán trong mổ $(n=44)$

\begin{tabular}{|c|c|c|c|c|c|c|}
\hline \multicolumn{2}{|c|}{$\begin{array}{c}\text { Hình ảnh } \\
\text { tổn thương }\end{array}$} & $\begin{array}{c}\text { Mò̀ đồng } \\
\text { nhất }\end{array}$ & $\begin{array}{c}\text { Mò̀ không } \\
\text { đồng nhất }\end{array}$ & $\begin{array}{c}\text { Hang dịch } \\
\text { khí }\end{array}$ & $\begin{array}{c}\text { Kén/hang } \\
\text { khí }\end{array}$ & Đa kén khí \\
\hline \multirow{2}{*}{ Tổng } & $\mathrm{n}$ & 12 & 14 & 9 & 8 & 1 \\
\cline { 2 - 7 } & $\%$ & 27,27 & 31,82 & 20,45 & 18,18 & 2,27 \\
\hline
\end{tabular}

Bảng 3.2: Hình ảnh chụp cắt lớp vi tính ngụcc $(n=46)$

\begin{tabular}{|c|c|c|c|c|c|c|c|}
\hline \multicolumn{2}{|c|}{$\begin{array}{c}\text { Hình ảnh tổn } \\
\text { thương }\end{array}$} & $\begin{array}{c}\text { Dạng } \\
\text { đặc }\end{array}$ & $\begin{array}{c}\text { Nang } \\
\text { dịch }\end{array}$ & $\begin{array}{c}\text { Mò̀ không } \\
\text { đồng nhất }\end{array}$ & $\begin{array}{c}\text { Kén/ hang } \\
\text { dịch khí }\end{array}$ & $\begin{array}{c}\text { Kén khí/ } \\
\text { hang khí }\end{array}$ & Đa kén \\
\hline \multirow{2}{*}{ Tổng } & $\mathrm{n}$ & 6 & 13 & 10 & 7 & 8 & 2 \\
\cline { 2 - 8 } & $\%$ & 13,04 & 28,26 & 21,74 & 15,21 & 17,39 & 4,35 \\
\hline
\end{tabular}

39 trường hớp phát hiện mạch bất thường: 24 (52,17\%) từ chủ ngực, 11 (23,91\%) từ chủ bụng, $4(8,7 \%)$ từ động mạch than tạng, 7 trường hợp không phát hiện mạch.

Số lượng mạch bất thường chủ yếu 1 mạch 76,09 \%, trên 2 mạch 8,7 \%.

Bên tổn thương phải/trái: $18 / 28$

\subsection{5. Đặc điểm cấu trúc động mạch bất thường}

Vi thể mạch bất thường có 6 trường hơp mô tả: 3/ 6 truòng hợp động mach chun, 3/6 truò̀ng hơp thành mach xo dày.

\section{2. Điều trị phẫu thuật}

\subsubsection{Chẩn đoán trước mổ}

39/46 (84,78\%) trường hợp chẩn đoán chính xác trước mổ, $1 / 46(2,17 \%)$ theo dõi phổi biệt lập. 6 trường hợp chẩn đoán các bệnh khác: U phổi 2/46 trường hợp, Phổi đa kén 1/46 trường hợp, u trung thất 1/46 trường hợp, giãn phế quản $1 / 46$ trường hợp.

3.2.2. Chẩn đoán sau mổ và xử lý phổi biệt lập $(n=46)$

Phổi biệt lập trong thùy 40 truờng hơp: $95 \%$ cắt thùy phổi, 5\% cắt phân thùy. Phổi biệt lập ngoài thùy 6 truờng hợp: 33,33\% cắt nguyên phổi biệt lập, $50 \%$ có cắt thùy phổi kèm theo, $16,67 \%$ cắt 1 phần thùy phổi kèm theo.

Số luọng mạch bất thuò̀ng trong mổ: 1 mach 80,43\%, 2 mach 4,35\%, 3 mach 8,7\%, 4 mach 6,52\%.
Nguyên ủy động mạch bất thwờng: 27 $(58,7 \%)$ trường hơp tù động mạch chủ ngục có 4 truò̀ng hợp đi vào tổn thuơng bên phải, 23 trưòng hợp cho tổn thuoong bên trái. 19 (41,3\%) tù động mạch chủ bụng có 14 trường hợp cho tổn thuoong bên phải, 5 trường hơp cho tổn thuoong bên trái.

Thời gian mổ trung bình: 200,87 $\pm 59,4$ phút. Min: 105 phút; Max: 330 phút. Không viêm dính : 161,54 phút, có viêm dính: 216,36 phút.

Biến chúng trong mổ: 2/46 trường hợp rách cơ hoành, 44/46 trường hợp không biến chứng, không có biến chứng liên quan tới mạch bất thường.

\subsubsection{Biến chứng sau mổ}

Có 27 trường hợp không biến chưng sau mổ, 19 trường hợ có biến chứng sau mổ trong đó: Rò khí kéo dài 13,04\%, Ổ dịch khu trú 13,04\%, chảy máu 4,35\%, xẹp phổi 4,35\%, rò thực quản 2,17\%, rò duõng chấp 2,17\%, nhiếm trùng vết mổ $2,17 \%$.

14/28 (50\%) trường hợp có có tiền sủ hô hấp có biến chứng sau mổ. 5/18(27,78\%) trường 
hợp không có tiền sử bệnh hô hấp có biến chưng sau mổ, với tỷ xuất chênh $O R=2,6$.

\subsubsection{Số ngày dẫn lưu sau mổ, số ngày} nằm viện (trừ trường họp rò thực quản)

Số ngày dẫn luu sau mổ trung bình 8,11 \pm 4,08 ngày, thấp nhất 3 ngày, lâu nhất 22 ngày, Không biến chứng 6,6 3,04 ngày, có biến chưng

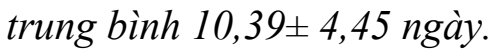

Số ngày nằm viện trung bình sau mổ: 16,2 $\pm 12,84$ ngày. Không biến chứng 11,81 $\pm 5,4$ ngày, Có biến chứng 22,78 $\pm 17,49$ ngày.

3.2.5. Kết quả phẫu thuật: Tốt (các truờng hợp sau mổ không có biến chứng): 58,7\%, trung bình (các trường hợp có biến chứng nhưng không can thiệp phẫu thuật): 32,6\%, Xấu (các truờng hợp có biến chứng phải can thiệp phẫu thuật): $8,7 \%$.

\section{BÀN LUẬN}

\subsection{Mộ số đặc điểm dịch tễ}

\subsubsection{Theo tuổi}

Tuổi trung bình 33 tuổi nói lên việc phát hiện và điều trị ở nước ta còn rất muộn. Tương tự với các nghiên cứu trong nước và thế giới đều cho thấy bệnh thường được chẩn đoán và điều trị muộn.

\subsubsection{Theo giới}

Tỷ lệ bệnh gặp ở nữ chiếm ưu thế với tỷ lệ nam/ nữ: $1 / 1,56$, sự khác biệt không có ý nghĩa thống kê với $\mathrm{p}=0,14>0,05$

\subsection{Tiền sử bệnh}

$28 / 46(60,87 \%)$ số trường hợp có tiền sử chẩn đoán và điều trị các bệnh hô hấp. Dường như bệnh phổi biệt lập biểu hiện sớm nhưng thường bị chẩn đoán sang các bệnh hô hấp khác. Tác giả Dirk Van Raemdonck [2], cũng như nhiều tác giả xếp vào nhóm dấu hiệu và triệu chứng của bệnh như: bệnh nhân có viêm phổi, nhiễm trùng mạn tính tái phát, ho máu đó là dấu hiệu gợi ý đến phổi biệt lập.

\section{phổi biệt lập}

4.3. Triệu chứng lâm sàng chủ yếu của

\subsubsection{Triệu chứng cơ năng chủ yếu}

Các triệu chứng của phổi biệt lập khi có biến chứng rất đa dạng giống các bệnh lý hô hấp khác: đau ngực, sốt, ho, ho máu, khó thở..., không đặc hiệu. Nhưng khi có tiền sử bệnh hô hấp đặc biệt viêm phổi hay viêm đường hô hấp tái diễn thì cần phải nghĩ tới phổi biệt lập. Kết quả nghiên cứu các triệu chứng hay gặp của bệnh cũng tương tự như các tác giả trong nước và thế giới: Nguyễn Chi Lăng (2005) [3], triệu chứng chủ yếu tập trung vào ho, ho khạc mủ, ho máu, sốt, đau ngực. Savic nghiên cứu 540 trường hợp phổi biệt lập, phổi biệt lập trong thùy $37,2 \%$ trường hợp có triệu chứng xuất hiện trước 10 tuổi, $15,5 \%$ trường hợp không triệu chứng, còn lại triệu chứng chủ yếu: ho, ho khạc đờm, viêm phổi tái diễn, trong khi đó phổi biệt lập ngoài thùy có $60 \%$ biểu hiện triệu chứng trước 10 tuổi [1]. Jolanta Hauer (2007) [4], ho, ho khạc đờm, sốt, đau ngực, ho máu là các triệu chứng chủ yếu.

\subsection{Cận lâm sàng}

\subsubsection{XQuang ngục thưòng quy (bảng 1.)}

\subsubsection{Bên thuoơng tổn}

Tương tự trong các nghiên cứu khác, kết quả nghiên cứu cho thấy Phổi biệt lập tổn thương bên trái chiếm ưu thế với tỷ lệ phải/ trái: 18/28 =1/1,56.

\subsubsection{Hình ảnh tổn thương XQuang}

Phổi biệt lập hình ảnh chủ yếu trên XQuang ngực thường quy có tính chất gợi ý: tổn thương khu trú thùy dưới phân thùy đáy sau, đặc biệt bên trái thì cần nghĩ đến phổi biệt lập. Các nghiên cứu trong nước: Nguyễn Chi Lăng thấy ưu thế phổi bên trái cao hơn hẳn so bên phải. Tổn thương theo tác giả này nằm phân thùy 10 và hình ảnh có 3 dạng: mờ không đồng đều bờ không gọn, mờ không đồng đều có mức nước mức hơi, mờ đều gọn dạng u [3]. Tác giả Đinh Văn Lượng phân tích hình ảnh trên phim XQuang thành các dạng 
tổn thương: dạng $\mathrm{u}$, dạng viêm dạng kén có mức dịch khí hoặc không [5]. Savic nghiên cứu 540 trường hợp phổi biệt lập, tỷ lệ phải/ trái: 1/1,7. Trong 100 trường hợp chụp XQuang phổi biệt lập trong thùy có hình ảnh tổn thương chủ yếu: nang 52 trường hợp, mức dịch 26 trường hợp, mờ đồng nhất 32 trường hợp, mờ không đồng nhất 16 trường hợp. Số ít còn lại có hình ảnh khoảng trống sau tim, nhiều mức dịch khí. Ngoài ra tác giả còn mô tả 6 trường hợp có cả phổi biệt lập trong thùy và ngoài thùy, vị trí phổi biệt lập ngoài thùy có thể cùng bên với phổi biệt lập trong thùy hay ở bất cứ vị trí nào trong ngực [1]. Theo Yong Wei, 1159 trường hợp chụp $\mathrm{x}$ quang ngực hình ảnh tổn thương, chủ yếu: khối (532 trường hợp 46,38\%), nang (424 trường hợp 36,58\%), khoang trống (69 trường hợp, 5,87\%), viêm phổi (118 trường hợp, $10,18 \%$ ) [6].

\subsubsection{Chụp cắt lớp vi tính ngục có tiêm thuốc cản quang}

Hình ảnh tổn thương trên phim cắt lớp vi tính ngực rõ ràng hơn, nhưng cần chú ý các bất thường mạch máu xung quanh tổn thương trên. Trong nghiên cứu có 39 trường hợp phát hiện mạch bất thường, 7 trường hợp không phát hiện mạch (Bảng 2). Số lượng mạch bất thường chủ yếu 1 mạch 76,09\%, trên 2 mạch 8,7\%. Theo các tác giả trong nước và nước ngoài như: Nguyễn Chi Lăng chỉ có 4 trường hợp được chụp cắt lớp vi tính thì 3 trường hợp dạng áp xe, 1 trường hợp dạng u [3]. Theo các tác giả trên thế giới như Yong Wei, 1106 trường hợp chụp cắt lớp vi tính ngực thấy tổn thương chủ yếu: khối $(49,01 \%)$, nang $(28,57 \%)$, khoang chống $(11,57 \%)$, các tác giả khác cho là khí thũng của phổi hay kén khí của phổi chúng tôi là kén khí hay hang không có mức nước hơi), viêm phổi $(7,96 \%)$ [6]. Nhờ có chụp cắt lớp vi tính đa dãy và cắt lớp vi tính mạch đã thấy được mạch máu bất thường từ động mạch chủ, theo Yong Wei 1808 trường hợp thấy nguyên ủy động mạch bất thường chủ yếu động mạch chủ ngực (76,55\%), từ động mạch chủ bụng $(18,475)$, số còn lại từ các động mạch khác. Số lượng mạch bất thường 813 trường hợp chủ yếu 1 mạch $(97,09 \%), 2$ mạch $(15,99 \%)$, trên 2 mạch $(4,92 \%)[6]$.

\subsubsection{Giải phẫu bệnh động mạch bất thưòng sau mổ}

Mô tả vi thể mạch bất thường ít được mô tả, chỉ có 6 trường hợp mô tả động mạch bất thường là cấu trúc chun và thành mạch xơ dày. Tác giả Savic [1] vi thể động mạch bất thường là cấu trúc sợi chun chiếm ưu thế và sự biến đổi thông thường thành xơ cứng mạch thậm trí ngay ở trẻ nhỏ, điều này đặc biệt quan trọng với phẫu thuật viên phải biết để tránh biến chứng trong phẫu thuật liên quan tới động mạch bất thường này.

\section{6. Điều trị}

\subsubsection{Chẩn đoán trước và trong mổ}

Phổi biệt lập trong thùy chẩn đoán đúng trước mổ 40/46 trường hợp, 6/ 46 trường hợp chẩn đoán nhầm các bệnh khác: u phổi, u trung thất, kén phế quản, phổi đa kén do trên phim chụp cắt lớp vi tính ngực không phát hiện mạch bất thường. Theo Savic trong 100 trường hợp phổi biệt lập trong thùy chỉ có 39 trường hợp chẩn đoán chính xác phổi biệt lập trong thùy, 8 trường hợp chẩn đoán theo dõi phổi biệt lập [1]. Yong Wei, trong 2625 trường hợp có tới 713 trường hợp chẩn đoán nhầm trước phẫu thuật [6]. Như vậy ngay cả phim chụp cắt lớp vi tính ngực cũng có chẩn đoán nhầm do hình ảnh thương tổn giống các bệnh thông thường hoặc các mạch máu bất thường thực sự khó thấy trên phim chụp.

\subsection{2. Điều trị phẫu thuật}

4.6.2.1. Mạch bất thuoòng phát hiện trong mổ 7 trường hợp không phát hiện mạch bất thường trên phim cắt lớp vi tính ngực thì 4 trường hợp từ động mạch chủ ngực, 3 trường hợp từ động mạch dưới cơ hoành (động mạch chủ bụng). Số lượng mạch bất thường phát hiện trong mổ nhiều nhất 4 
mạch. Như vậy luôn luôn cảnh giác với các mạch bất thường cũng như số lượng mạch nhằm hạn chế các biến chứng với mạch này. Các tổn thương bên trái nguyên ủy chủ yếu từ động mạch chủ ngực 23/28 (82,14\%) trường hợp, còn tổn thương bên phải nguyên ủy lại chủ yếu từ động mạch chủ bụng 14/18 (77,78\%) trường hợp, sự khác biệt này có ý nghĩa thống kê với $\mathrm{p}<0,05$. Điều này giúp cho chúng ta tìm các mạch bất thường tránh bỏ sót các mạch này ngay cả các phim chụp không dựng hình mạch máu.

\subsubsection{2. Điều trị phổi biệt lập triệt để là} phẫu thuật cắt bỏ phổi biệt lập càng sớm càng tốt, đặc biệt chú ý các mạch máu bất thường hạn chế tối đa biến chứng liên quan tới các mạch máu này. Với phổi biệt lập trong thùy chủ yếu cắt thùy chỉ có ít trường hợp bảo tồn được phần phổi lành, trong khi đó phổi biệt lập ngoài thùy chỉ có $2 / 6$ trường hợp cắt được nguyên Phổi biệt lập còn lại phải cắt thùy hoặc phân thùy lân cận do viêm dính phá hủy phổi lành. Tại bệnh viện Nhi trung ương tác giả Tô Mạnh Tuân đã báo cáo ca mổ thành công bằng Robot điều trị phổi biệt lập phối hợp dị dạng nang tuyến bẩm sinh ở bệnh nhi đây là ứng dụng công nghệ hiện đại trong điều trị [7]. Peter B. Kestonholz, ứng dụng phẫu thuật nội soi trong điều trị phổi biệt lập 13 trường hợp phổi biệt lập trong thùy, trong đó 1 trường hợp phải chuyển mổ mở vì móc đốt nội soi vào động mạch bất thường, 12 trường hợp còn lại thì 8 trường hợp cắt thùy phổi, 4 trường hợp cắt phân thùy không điển hình, 1 trường hợp biểu hiện chủ yếu ho máu nên động mạch bất thường đã được làm tắc bằng cắt stapler ngay từ đầu. 1 trường hợp cắt bỏ phổi biệt lập ngoài thùy. Thời gian mổ trung bình 133 phút. So với nghiên cứu của chúng tôi thì thời gian phẫu thuật nhanh hơn, có lẽ do tình trạng viêm dính kéo dài mà dẫn tới sự khác biệt này có ý nghĩa thống kê với $\mathrm{p}<0,05$ [8].

Tác giả Savic [1] cũng như các tác giả Halkic [9], cho biết phổi biệt lập được cắt bỏ ra sao: cắt phổi biệt lập, cắt thùy chứa phổi biệt lập hay cắt phân thùy chứa phổi biệt lập.

\subsubsection{Biến chứng trong mổ và sau mổ}

2/46 trường hợp có biến chứng trong mổ làm rách cơ hoành trong quá trình gỡ dính, không có trường hợp nào biến chứng liên quan tới mạch bất thường. Trong 28 trường hợp có có tiền sử hô hấp thì có tới $50 \%$ biến chứng sau mổ, trong khí đó các trường hợp không có tiền sử bệnh hô hấp thì chỉ có $27,78 \%$ có biến chứng sau mổ, với tỷ xuất chênh $\mathrm{OR}=2,6$ thì nhóm có tiền sử bệnh hô hấp có nguy cơ có biến chứng sau mổ cao gấp 2,6 lần so với nhóm không có tiền sử bệnh hô hấp.

Các biến chứng sau mổ thường nhẹ xử lý đơn giản. Đặc biệt có trường hợp rò thực quản sau mổ, bệnh nhân sau mổ phải thực hiện thêm nhiều thủ thuật và phẫu thuật hỗ trợ, thời gian nằm viện kéo dài $>375$ ngày. Có lẽ đây là trường hợp phổi biệt lập có phối hợp với rò đường tiêu hóa hoặc do viêm dính làm thay đổi giải phẫu khi phẫu thuật cũng khó tránh được tổn thương vào thực quản. Theo Savic B phổi biệt lập có kèm theo các dị dạng trong đó rò thực quản phế quản trong phổi biệt lập ngoài thùy, nang thực quản phế quản trong phổi biệt lập trong thùy, ngoài ra còn có các dị dạng cơ hoành, hệ xương, tim mạch [1]. Peter $\mathrm{B}$. Kestonholz có trường hợp biến chứng tổn thương mạch bất thường phải chuyển mổ mở[8].

\subsubsection{Số ngày dẫn luu và điều trị sau mổ}

Thời gian rút dẫn lưu lâu do đây là phẫu thuật nhiễm trùng viêm dính của phổi, và cần chẩn đoán và can thiệp sớm nhất có thể bệnh lý này. Thời gian nằm viện sau phẫu thuật trong nghiên cứu của chúng tôi là lâu hơn so với tác giả Peter $\mathrm{B}$. Kestonholz thời gian nằm viện trung bình sau phẫu thuật 7,5 ngày[8] sự khác biệt có ý nghĩa thống kê với $\mathrm{p}<0,05$. Nhưng tương tự so với tác giả Dirk Van Raemdonck thời gian nằm viện trung bình sau mổ 13 ngày[2] sự khác biệt không có ý nghĩa thống kê với $\mathrm{p}=0,5>0,05$. 


\subsubsection{Kết quả phẫu thuật}

Hầu hết các tác giả đều nhận định phẫu thuật phổi biệt lập mang lại kết quả tốt, tỷ lệ thành công cao, ít tai biến nặng nề.

\section{KẾT LUẬN}

Phổi biệt lập là dị tật bẩm sinh cần được chẩn đoán sớm dựa vào chụp $\mathrm{CT}$ scan ngực có dựng hình mạch máu và điều trị triệt để bằng phẫu thuật cáng sớm càng tốt. Cần phải nghĩ tới phổi biệt lập khi có tiền sử hô hấp + tổn thương trên xquang ngực thường quy ở đáy sau dưới của ngực đặc biệt bên trái.

\section{TÀI LIỆ THAM KHẢO}

1. Savic, B., et al., Pulmonary sequestration. Ergeb Inn Med Kinderheilkd, 1979. 43: p. 57-92.

2. Van Raemdonck, D., et al., Pulmonary sequestration: a comparison between pediatric and adult patients. Eur J Cardiothorac Surg, 2001. 19(4): p. 388-95.

3. Nguyễn Chi Lăng, Nghiên cứu đặc điểm lâm sàng, xét nghiệm của 12 truờng hợp phổi biệt lập trong thùy. y học thực hành, 2007. 5: p. 76-78.
4. Hauer, J., et al., Pulmonary Sequestration-Analysis of Diagnostic and Therapeutic Difficulties. Polish Journal of Surgery, 2007. 79(1): p. 24-28.

5. Đinh Văn Lượng, K.M.C., Đoàn Quốc Hưng,, Nghiên cứu đặc điểm lâm sàng, cận lâm sàng và kết quả phẫu thuật phổi biệt lập. tạp chí Phẫu thuật tim mạch và lồng ngực Việt Nam, 2015. 11: p. 41-45.

6. Wei, Y. and F. Li, Pulmonary sequestration: a retrospective analysis of 2625 cases in China. European Journal of CardioThoracic Surgery, 2011. 40(1): p. e39-e42.

7. Tô Mạnh Tuân, Hoàng Ngọc Thạch, and Nguyễn Mạnh Hoàn và cộng sự, Nội soi Robot cắt thùy phổi dị dạng nang tuyến bẩm sinh phối hơp phổi biệt lập ở tre em nhân một truờng hơp. Y Học Việt Nam, 2014. 2: p. 109-113.

8. Kestenholz, P.B., et al., Thoracoscopic treatment of pulmonary sequestration. European journal of cardio-thoracic surgery, 2006. 29(5): p. 815-818.

9. Halkic, N., et al., Pulmonary sequestration: a review of 26 cases. Eur J Cardiothorac Surg, 1998. 14(2): p. 127-33. 